\title{
A greve como direito fundamental: conteúdo essencial e a (im)possibilidade de sua limitação infraconstitucional
}

The strike as fundamental law: essential content and (im) possibility of its infra constitutional limitation

A greve como derecho fundamental: contenido esencial y la (im) posibilidad de su limitación infraconstitucional

Debora Markman Universidade Metodista de Piracicaba - UNIMEP

Mário Lúcio Garcez Calil Universidade do Mato Grosso do Sul - Unidade Universitária de Paranaíba

Resumo O objetivo deste trabalho é estudar a natureza jurídica do direito de greve, bem como, as possibilidades de sua limitação, por meio de pesquisa bibliográfica e documental, voltada a determinar as possibilidades de restrição ao direito de greve, por intermédio das teorias relacionadas à ponderação, ao conteúdo essencial e ao suporte fático dos direitos fundamentais. Justifica-se o presente trabalho em decorrência da importância do direito de greve para as reivindicações dos trabalhadores e para o exercício efetivo da democracia.

Palavras-chave: Direito de Greve. Ponderação. Conteúdo Essencial. Suporte Fático. Direitos Fundamentais. 
Abstract The objective of this work is to study the legal nature of the right to strike, as well, as the possibilities of its limitation, through bibliographical and documentary research, aimed at determining the possibilities of restricting the right to strike, through related theories weighting, essential content and factual support of fundamental rights. This work is justified because of the importance of the right to strike for worker's demands and for the effective exercise of democracy.

Keywords: Right of Strike. Weighting. Essential Content. Factual Support. Fundamental Rights.

Resumen El objetivo de este trabajo es estudiar la naturaleza jurídica del derecho de huelga, así como, las posibilidades de su limitación, por medio de investigación bibliográfica y documental, volcada a determinar las posibilidades de restricción al derecho de huelga, por intermedio de las teorías relacionadas a la ponderación el contenido esencial y el soporte fáctico de los derechos fundamentales. Se justifica el presente trabajo como consecuencia de la importancia del derecho de huelga para las reivindicaciones de los trabajadores y para el ejercicio efectivo de la democracia.

Palabras clave: Derecho de Huelga. Ponderación. Contenido esenCial. Soporte Técnico. Derechos Fundamentales.

\section{INTRODUÇÃO}

O direito de greve consta da Constituição Federal de 1988, no título relacionado aos direitos fundamentais. Ocorre que, como os demais direitos dessa espécie, o direito de greve não é ilimitado. Desse modo, o objetivo do presente trabalho é estudar a natureza jurídica do direito de greve, bem como, as possibilidades de sua limitação.

Para tanto, procedeu-se à pesquisa bibliográfica e documental, voltada a determinar as possibilidades de restrição ao direito de greve, por intermédio das teorias relacionadas à ponderação, ao conteúdo essencial e ao suporte fático dos direitos fundamentais. Na escrita, utilizou-se o procedimento dedutivo. 
$\mathrm{O}$ trabalho restou dividido em cinco partes. Na primeira foram tratadas as questões jurídico-históricas relacionadas ao direito de greve. A seguir, foi estudada a sua natureza jurídica e a (des)necessidade de sua regulamentação, sua "eficácia", sua estrutura normativa, bem como, a sua "fundamentalidade".

Na sequência, foi estudado o conteúdo essencial do direito fundamental de greve, no contexto das teorias acerca do conteúdo essencial dos direitos fundamentais (absoluta e relativa). Após, foi estudado o suporte fático do direito fundamental de greve e suas teorias (restrita e ampla), bem como, as restrições ao direito de greve na Lei 7.783, de 1989.

Por último, foi abordado a ponderação e o direito de greve na jurisprudência. Justifica-se a pesquisa ora apresentada, em decorrência da evidente importância do direito fundamental de greve tanto para as reivindicações dos trabalhadores, quanto para o exercício efetivo da própria democracia.

\section{O DIREITO FUNDAMENTAL DE GREVE: QUESTÕES JURÍDICO- -HISTÓRICAS}

A história do direito de greve revela sua intrínseca ligação com os movimentos coletivos de trabalhadores, desde suas origens (MELLO, 1980, p. 18). No mesmo sentido, demonstram-se tentativas as mais diversas de restrição desse direito, em nome dos mais variados fatores, sejam eles sociais ou econômicos.

Antes da Revolução Francesa há registros de que a movimentação de trabalhadores tenha sido considerada infração penal grave. Em 1791, por exemplo, surgiu a Lei Le Chapelier, que sancionava criminalmente os patrões que contratassem trabalhadores participantes de movimentos grevistas, atentatórios à ordem pública (MELLO, 1980, p. 19-20).

Evidentemente que, no período, não se cogitava a existência de um conjunto de prerrogativas laborais. Apesar disso, já se identificavam movimentos classistas, voltados à obtenção dessa sorte de direitos, apesar da ausência de formalização ou de sua garantia pelo Estado. 
Ante tal registro, é possível inferir que a negociação coletiva trabalhista transcende o Direito do Trabalho. Desde o século XIX, a dinâmica da negociação trabalhista coletiva influenciou a estruturação democrática em vários países (DELGADO, 2009, p. 1.259), tendo sido responsável, em grande parte, pelo surgimento desse ramo jurídico.

Nesse período, as indústrias eram verdadeiros agrupamentos humanos, ocasionados pelo Revolução Industrial. Se, por um lado, esse período não pode ser citado como grande contribuinte positivo para as políticas relativas ao trabalho, na medida em que as condições de trabalho eram extremamente degradantes, por outro, propiciou avanços da legislação trabalhista, alcançadas pela luta dos trabalhadores.

As tensões e os fatos políticos sociais geraram instabilidades, que repercutiriam na situação dos trabalhadores, com redução de salários e dispensa em massa (MELLO, 1980, p. 20).

As queixas eram comuns, de modo que a ação conjunta seria a primeira das consequências. A partir desse momento histórico, várias greves ocorreram no mundo: entre 1879 a 1899 , na Itália, cerca de 2.483 vezes; na Inglaterra, só em 1889 foram registrados 1.145 movimentos grevistas (MELLO, 1980, p. 20).

O Brasil, ${ }^{1}$ no final do século XIX, parece ter se adiantado em

\footnotetext{
Os principais dispositivos normativos do Ordenamento Jurídico Brasileiro: O Código Penal (1890) proibia a greve e, até o advento do Decreto n. 1.162, de 12.12.1890, essa orientação foi mantida; A Lei nº. 38, de 04.04.1932 (segurança nacional), conceituou a greve como delito. As Constituições brasileiras de 1891 e de 1934 foram omissas a respeito da greve; A Constituição de 1937 prescrevia a greve e o lockout como "recursos anti-sociais, nocivos ao trabalho e ao capital e incompatíveis com os superiores interesses da produção nacional".

O Decreto-lei $\mathrm{n}^{\circ}$. 431, de 18.05.1938 (também versava sobre segurança nacional), tipificou a greve como crime, no que diz respeito ao incitamento dos funcionários públicos à paralisação coletiva dos serviços. O Decreto-lei n ${ }^{\circ}$. 1.237, de 02.05.1939, que instituiu a Justiça do Trabalho, previa punições em caso de greve, desde a suspensão e a dispensa por justa causa até a pena de detenção. O Código Penal, de 7.12.1940 (arts. 200 e 201), considerava crime a paralisação do trabalho, na hipótese de perturbação da ordem pública ou se o movimento fosse contrário aos interesses públicos. O Decreto-lei $\mathrm{n}^{\circ}$. 9.070, de 15.03.46, passou a tolerar a greve nas atividades acessórias, não obstante a proibição prevista na Constituição de 1937. Nas atividades fundamentais, contudo, permanecia a vedação. A Constituição de 1946 reco-
} 
relação ao reconhecimento da "legitimidade dos movimentos paredistas laborais", mesmo não o tendo reconhecido, naquele período, como um efetivo direito, muito menos de natureza fundamental, já que sua constitucionalização ainda demoraria algumas décadas (FONTE).

O Decreto 1.162 de 1890 não tornou a greve um direito, mas criou um novo contexto normativo, tornando-a um fato social, algo como uma liberdade, remetendo à necessidade do exame das situações concretas grevistas a pesquisa sobre ocorrência de atos de violência, constrangimento ou ameaça (DELGADO, 2009, p. 1.319).

Apesar de vedar a greve para as atividades fundamentais, tratou-se da primeira lei ordinária a aludir acerca da matéria, porém, com um texto que, apesar de reconhecer esse direito em algumas circunstâncias, era deveras restritivo (DELGADO, 2009, p. 1.319). Ocorre que os movimentos paredistas ainda aconteciam em profusão.

Em 1903, porém, cerca de 25 mil cocheiros e carroceiros do Rio de Janeiro paralisaram o transporte de passageiros, reivindicando melhores salários e, cerca de 40 mil tecelões se mobilizaram para reduzir sua jornada de trabalho, tendo logrado êxito, diminuindo para nove horas e meia por dia sua jornada diária (MELLO, 1980, p. 23).

Em 1906, em Porto Alegre, ocorreu a greve geral, à qual aderiram trabalhadores de variados segmentos, que conseguiram a redução de jornada de trabalho para nove horas de trabalho diárias. Em São Paulo, iniciando-se no Cotonifício Crespi, ${ }^{2}$ em junho de 1917, dois mil operários pediram 20\% de aumento salarial (MELLO, 1980, p. 23).

nheceu o direito de greve, mas o mesmo deveria ser regulamentado. A Constituição de 1967 garantia o direito de greve como não extensivo aos servidores públicos e a Constituição de 1988 amplia o direito de greve a todos no caput mas, de certa forma, limita no $\S 1^{\circ}$. para os servidores públicos pela necessidade de lei posterior.

2 O Cotonifício Crespi foi inaugurado em 1897, no bairro da Mooca, em um enorme prédio de três andares na esquina da rua dos Trilhos com a rua Taquari com quase 50 mil $\mathrm{m}^{2}$ de área construída, num terreno de $30 \mathrm{mil} \mathrm{m}^{2}$. Estabeleceu-se no ramo têxtil, importou alguns teares e adquiriu outros em São Paulo, criando o que seria o primeiro estabelecimento brasileiro de fiação industrial de algodão em grande escala. Em 1917, foi palco de uma das primeiras, e ainda a mais violenta, entre as greves já havidas no Brasil. Disponível em: $<$ https://lembrasp.blogspot.com/2017/01/cotonificio-rodolfo-crespi-inaugurado.html>. Acesso em: 18 nov. 2018. 
Esse movimento foi seguido por outras fábricas. Em 12 de junho, a paralisação atingiu 15 mil trabalhadores. Dois dias depois, contava com 40 mil e, daí, estendeu-se para Santos, Campinas, São Bernardo do Campo e outras cidades (MELLO, 1980, p. 23). Referidos movimentos, todavia, seriam apenas o embrião do efetivo reconhecimento desse direito.

Entre 1930 e 1945, implantou-se algo como um "modelo sindical brasileiro", porém, de cariz corporativo-autoritário, contrário às livres manifestações dos movimentos paredistas. Em 1946, com o Decreto-lei n. 9.070, resultante do processo de redemocratização, passou-se a admitir a greve nas atividades acessórias (DELGADO, 2009, p. 1.319-1.320).

Esse reconhecimento demonstra a relação direta que existe entre o direito de greve e os regimes democráticos: a História demonstra que os movimentos paredistas apenas são legítimos em regimes democráticos, bem como, que os Estados verdadeiramente embasados na democracia legitimam a greve. Isso porque em regimes não democráticos não existe a liberdade da livre associação, a liberdade de reunião, a liberdade de expressão. Nesse cenário, resta totalmente inviabilizado um movimento paredista que necessariamente carece de todas essas liberdades para se organizar, articular e se materializar.

A Constituição Francesa de 1946 proclamou o direito de greve e de eleição de delegados para participarem da gestão empresarial e da negociação coletiva. A Carta Italiana de 1947 determinou a remoção de obstáculos para a participação dos trabalhadores na organização política, econômica e social do país (SUSSEKIND, 1986, p. 25-26).

As Constituições brasileiras de 1934 e 1946 previram a denominada primazia da justiça social na ordem econômica, conciliando a livre iniciativa e a valorização do trabalho, reconhecendo o direito de greve e as convenções laborais coletivas (SUSSEKIND, 1986, p. 36). Após esse período, todavia, o autoritarismo regressaria à nação.

A Constituição de 1967 manteve esse direito, salvo para os serviços públicos e atividades essenciais. O Ato Institucional nº. 5, de 1968, agravou o autoritarismo do regime, inviabilizando as greves (DELGADO, 2009, p. 1.320-1.321).

A Constituição de 1988, entretanto, veio no sentido de reconhecer a greve como um direito fundamental, o que é reafirmado pela Lei 7.783/1989, que dispõe sobre o exercício desse direito. 


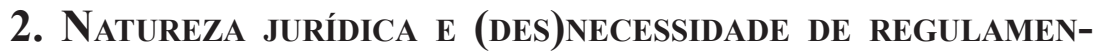 TAÇÃO}

Faz-se necessário, inicialmente, distinguir entre os institutos da greve e do direito de greve. Um não se confunde com o outro, até porque o primeiro é a materialização do segundo, no plano dos fatos. Mais do que isso, o primeiro é exercitado, de maneira legítima, por intermédio do segundo.

Quanto à greve em si, esta pode ser definida como uma abstenção de trabalhar em certas condições, com determinados fins, porém, mediante acordo, respeitando a todos os fenômenos complexos e diferenciados compreendidos sob essa nomenclatura na modernidade (RUPRECHT, 1995, p. 732).

Já em sentido jurídico, a greve consiste na suspensão temporária do trabalho, pactuada por um grupo organizado de trabalhadores, que abandonam seus respectivos locais de trabalho, de modo a pressionar os empregadores, e a defender seus interesses profissionais e econômicos (RUPRECHT, 1995, p. 738).

Faz-se necessário, todavia, trabalhar com maior profundidade o conceito e a mecânica do direito de greve, especialmente no que se relaciona à sua natureza jurídica, incluso à possibilidade de sua ponderação, nos casos concretos, com outros direitos, de conformidade com o que será tratado a seguir.

\subsection{A EFICÁCIA DO DIREITO DE GREVE}

O direito de greve é especificamente tratado no artigo $9^{\circ}$., da Constituição Federal de 1988 . $^{3}$ Seu caput é específico em assegurá-lo, deliberando aos trabalhadores a decisão acerca de seu exercício, bem como, em relação aos interesses a serem defendidos por seu intermédio, sem determinar qualquer restrição.

"Art. 9. É assegurado o direito de greve, competindo aos trabalhadores decidir sobre a oportunidade de exercê-lo e sobre os interesses que devam por meio dele defender" (BRASIL, 1988, s.n.p.). 
Trata-se, portanto, de uma das normas constitucionais a priori de eficácia plena que, na definição de José Afonso da Silva, regem, até onde possam, situações, comportamentos e atividades alcançáveis, condicionando as atividades dos órgãos públicos e criando situações jurídicas de vantagem ou vínculo (SILVA, 2003, p. 163-164).

Contudo, o parágrafo $1^{\circ}$. do referido dispositivo ${ }^{4}$ determina uma regulamentação infraconstitucional, relacionada aos serviços e atividades essenciais, bem como, em relação às necessidades inadiáveis da comunidade, ou seja, a eficácia não é plena para todos os trabalhadores, no caso, os servidores públicos. Em assim sendo, o caput do artigo $9^{\circ}$. a eles não se aplica, da qual é até possível afirmar se tratar de uma norma de eficácia limitada.

Ocorre que essas normas definem um direito de forma insuficiente, por ser impossível "aplicar" um direito sem se conhecer as hipóteses e condições para a sua incidência ou as formas de seu exercício (DIMOULIS; MARTINS, 2008, p. 105). Trata-se, porém, de uma norma restritiva que, todavia, necessita de regulamentação infraconstitucional.

Quanto aos servidores públicos, todavia, a Constituição dispõe de forma diversa, pois exige, expressamente, de acordo com o artigo 37, VII, ${ }^{5}$ a regulamentação infraconstitucional, por intermédio de lei específica. Trata-se, portanto, de uma norma constitucional de eficácia limitada, dependente de normatização legal para o seu exercício.

O Supremo Tribunal Federal decidiu que o direito à greve dos "trabalhadores em geral" não comporta limitações constitucionais, ao contrário do que ocorre em relação aos servidores públicos que, por sua, vez, necessitariam de regulamentação atinente ao seu próprio

4 “ $\$ 1^{\circ}$. A lei definirá os serviços ou atividades essenciais e disporá sobre o atendimento das necessidades inadiáveis da comunidade" (BRASIL, 1988, s.n.p.).

5 "Art. 37. A administração pública direta e indireta de qualquer dos Poderes da União, dos Estados, do Distrito Federal e dos Municípios obedecerá aos princípios de legalidade, impessoalidade, moralidade, publicidade e eficiência e, também, ao seguinte: [...] VII - o direito de greve será exercido nos termos e nos limites definidos em lei específica" (BRASIL, 1988, n.p.). 
exercício ${ }^{6}$ o que confirma tratar-se de uma norma constitucional de eficácia limitada.

\subsection{O DIREITO DE GREVE COMO DIREITO FUNDAMENTAL}

A constitucionalização do direito de greve, no Brasil, inseriu-o, em 1988, no Capítulo II ("Dos Direitos Sociais") do Título II ("Dos Direitos e Garantias Individuais"). Assim, ao menos no que concerne à topologia constitucional, trata-se, indubitavelmente, de um direito fundamental.

A greve tem natureza jurídica de direito fundamental coletivo, que resulta da autonomia privada coletiva característica das sociedades democráticas, como reconhecido pelo artigo $9^{\circ}$. da Constituição, como resultante da liberdade de trabalho, da liberdade associativa e sindical e da autonomia dos sindicatos. É, na atualidade, um direito essencial (DELGADO, 2009, p. 1.315).

Antes de definir as possibilidades de limitação ao direito fundamental à greve, faz-se necessário determinar sua estrutura normativa, se se trata de uma regra, obedecendo à lógica do tudo-ou-nada, ou de um princípio constitucional, podendo ser restringido somente por intermédio da utilização da técnica da ponderação.

\subsection{O DIREITO DE GREVE COMO PRINCÍPIO}

As diferenças entre princípios e regras é estrutural, demonstrando-

6 "A Constituição, ao dispor sobre os trabalhadores em geral, não prevê limitação do direito de greve, a eles compete decidir sobre a oportunidade de exercê-lo e sobre os interesses que devam por meio dela defender. Por isso a lei não pode restringi-lo, senão protegê-lo, sendo constitucionalmente admissíveis todos os tipos de greve. Todavia, na relação estatutária do emprego público não se manifesta tensão entre trabalho e capital, tal como se realiza no campo da exploração da atividade econômica pelos particulares. Neste, o exercício do poder de fato, a greve, coloca em risco os interesses egoísticos do sujeito detentor de capital - indivíduo ou empresa - que, em face dela, suporta, em tese, potencial ou efetivamente redução de sua capacidade de acumulação de capital" (BRASIL, 2008, n.p.). 
-se, inicialmente, pelo fato de que aqueles têm estrutura semântica mais ampla e abstrata do que as regras (DWORKIN, 2007, p. 102). Ocorre que as idiossincrasias de cada espécie normativa também se mostram por ocasião dos conflitos entre elas.

Princípios são normas que determinam que algo seja realizado na maior medida possível, dentro das possibilidades jurídicas e fáticas, verdadeiros mandamentos de otimização, que podem ser satisfeitos em vários graus. Essas possibilidades jurídicas são determinadas pelas colisões entre os princípios (ALEXY, 2008, p. 90).

Desse modo, especialmente em decorrência de sua amplitude semântica, a normatização dos princípios não pode ser aferida de pronto, em abstrato, mas somente a partir do resultado da operação de sopesamento, voltada a resolver, nos casos concretos, os conflitos entre os princípios.

Sua incidência não pode ser posta em termos de tudo ou nada, de validade ou invalidade, em decorrência de sua dimensão de peso ou importância, de modo que sua consecução é possível em menor ou maior grau. O sopesamento possibilita verificar qual princípio merece concretização mais intensa diante da situação concreta (CALIL; OLIVEIRA, 2008, p. 86).

De acordo com sua estrutura, a greve é, abstratamente, um princípio, o que se demonstra até mesmo em decorrência dos evidentes conflitos que podem ocorrer, por ocasião de seu exercício, com outros direitos fundamentais. Há, todavia, regras que necessitam ser cumpridas para o seu exercício constitucional e legalmente adequado.

Mesmo a operação de sopesamento, todavia, não é capaz de eliminar completamente a incidência de um princípio, especialmente no concernente àqueles que consagram os princípios. Tais operações, nesse sentido, determinam a preservação de um mínimo de normatividade: trata-se do denominado conteúdo essencial. 


\section{LIMITES E CONTEÚdO ESSENCIAL DO DIREITO FUNDAMENTAL DE GREVE}

A técnica do sopesamento é uma operação que deriva da necessidade de concretização do princípio constitucional da proporcionalidade que, por sua vez, determina ser imperiosa a aplicação adequada, necessária e razoável de uma norma principiológica ao caso concreto, especialmente em decorrência de seu conflito com outra norma da mesma espécie.

O princípio da proporcionalidade, na esfera jurídico-constitucional, vincula o legislador, de maneira reconhecida pela doutrina e pela jurisprudência, tendo evoluído do direito administrativo para o direito constitucional, especialmente em decorrência da interpretação britânica desse preceito (SCHOLLER, 1999, p. 94).

De acordo com ela, o Parlamento poderia fazer tudo, "menos transformar um homem numa mulher e uma mulher num homem", ${ }^{7} \mathrm{de}$ forma que apenas a lei natural seria capaz de limitar o legislador eleito democraticamente, elevado a um poder soberano, portanto, sem qualquer vinculação às suas competências constitucionais (SCHOLLER, 1999, p. 94).

A sede material do princípio é o Estado de Direito que, portanto, vincula o legislador e fundamenta o denominado princípio da reserva de lei proporcional (SCHOLLER, 1999, p. 97). Ocorre que não apenas a função estatal legiferante se encontra vinculada, pois também o estão todos os intérpretes da Constituição, em especial os juridicamente legitimados.

Do conflito entre os princípios nasce uma regra de direito fundamental aplicável ao caso concreto. Os princípios não são mandamentos definitivos, mas configuram princípios prima facie. Assim, não estendem seus conteúdos em relação ao princípio colidente e às possibilidades fáticas concretas, pois um princípio passa a pesar mais do que o outro (ALEXY, 2008, p. 104-105).

7 The parliament can do anything, but not change a man into a woman or a woman into a man. 
O sopesamento entre princípios conflitantes busca encontrar a solução proporcional para os problemas concretos. A ponderação complementa os métodos tradicionais de interpretação, de modo a atribuir sentido às prescrições normativas, especialmente nos casos difíceis, nos quais a determinação da norma aplicável necessita do juízo de ponderação (PEREIRA, 2006, p. 295).

Apesar de determinar a regra aplicável para o caso concreto, a operação de sopesamento não pode eliminar completamente a incidência daquele princípio que foi, no caso, derrotado. Existe a necessidade de se preservar o denominado conteúdo essencial do princípio que não incidirá no caso concreto.

\subsection{TEORIAS ACERCA DOS LIMITES AOS DIREITOS FUNDAMENTAIS E} SEU CONTEÚDO ESSENCIAL

O denominado princípio da proteção do conteúdo essencial é um limite dos limites dos direitos fundamentais, inferido logicamente do sistema de rigidez constitucional, a determinar a impossibilidade de eliminação total de um direito fundamental, mesmo que tenha sido derrotado no conflito com outro princípio (PEREIRA, 2006, p. 376-377).

Nesse sentido, um dos elementos que compõem o suporte fático dos direitos fundamentais é a restrição constitucionalmente fundamentada. A construção sobre o conteúdo essencial dos direitos fundamentais é necessária para a aplicação dessa teoria ao regime dos direitos fundamentais da Constituição de 1988 (CALIL, 2012, p. 82).

Ocorre que há, no mínimo, duas teorias voltadas a definir o que seria o núcleo essencial de um direito fundamental, denominadas, respectivamente, teoria do núcleo essencial absoluto e teoria do núcleo essencial relativo, que serão tratadas nos tópicos a seguir, em sua relação específica com o direito fundamental de greve.

\subsection{LIMITES IMANENTES E NÚCLEO ESSENCIAL ABSOLUTO}

A denominada teoria interna dos limites aos direitos fundamentais determina que a própria Constituição estabelece limites prévios, ima- 
nentes, aos direitos fundamentais. A teoria do núcleo essencial absoluto relaciona-se diretamente à teoria dos limites imanentes aos direitos fundamentais (SILVA, 2009, p. 157).

Em decorrência da referida teorização, cada direito fundamental possuiria um núcleo intangível, no qual não se poderia, jamais, interferir (ALEXY, 2008, p. 298). Desse modo, os limites aos direitos fundamentais são definidos em abstrato, sem a necessidade de sua aferição concreta.

Caso não exista norma na Constituição que expressamente autorize o legislador a restringir os direitos, este somente pode expor ou especificar os limites já contidos na norma, salvo se o texto constitucional possibilitar a interferência legislativa. Essa "esfera intangível" é, justamente um núcleo fixo, que independe de ponderação (PEREIRA, 2006, p. 140-372).

O conteúdo essencial é sempre o mesmo, de modo que a teoria absoluta o entende como algo estático e incondicional, que não pode ser ultrapassado. Desse modo "[...] o direito fundamental pode ser desdobrado em duas partes: uma parte essencial, e, portanto, inviolável, e uma parte não essencial, que pode ser objeto de restrição" (PEREIRA, 2006, p. 140-372).

Trata-se, porém, de uma teoria problemática, especialmente porque as estratégias hermenêuticas que se voltam a demarcar esse perímetro intangível podem resultar em subjetivismos e em arbitrariedades, isso porque se ignora a necessidade de ponderação entre princípios (PEREIRA, 2006, p. 374).

Essa teoria implica na rigidez dessas limitações, de modo que é impossível se desvencilhar o direito de sua restrição. Unificando-se o direito e seus limites imanentes, ignora-se a relação de precedência prima facie entre os princípios jurídicos e, por conseguinte, a possibilidade de conflitos entre essas normas (CALIL, 2012, p. 80).

A decisão acerca de princípios deve passar pela técnica da ponderação. Tendo em vista que a teoria do conteúdo essencial absoluto dispensa sua utilização, essa tese não pode construir adequadamente um regime jurídico dos direitos fundamentais da Constituição Federal de 1988 (CALIL, 2012, p. 83). 
Nesse sentido, a Constituição não determina limitação alguma ao direito fundamental de greve, salvo aquelas que, nos termos do parágrafo $1^{\circ}$. do artigo $9^{\circ}$., no qual o direito de greve deve ser determinado por lei ordinária. Desse modo, eventual conflito entre o referido direito e outro princípio constitucional deve ser resolvido por intermédio da operação de ponderação.

\subsection{TEORIA EXTERNA DOS LIMITES E NÚCLEO ESSENCIAL RELATIVO}

A teoria externa dos limites aos direitos fundamentais determina que não poderá haver qualquer restrição em abstrato a um direito fundamental, senão que precisam ser determinados em concreto, caso a caso. Liga-se, diretamente, à denominada teoria do núcleo essencial relativo e aos seus efeitos práticos.

Toda restrição a um direito fundamental deve ser identificada por meio da colisão, a atribuir maior peso a um dos princípios colidentes. Nesse sentido, para essa teoria, o conteúdo essencial é o princípio que se sobressai, após o sopesamento, a permitir que as restrições obedeçam à máxima da proporcionalidade (ALEXY, 2008, p. 296-298).

A garantia do conteúdo essencial não cria limites adicionais à possibilidade de restrição dos direitos fundamentais, pois equivale a uma parcela da proporcionalidade que, nesse sentido, fortalece a exigência de sua aplicabilidade. Assim, a possibilidade de limitação a um direito fundamental se deve extrair do caso concreto (ALEXY, 2008, p. 301).

$\mathrm{Na}$ teoria externa das restrições aos direitos fundamentais, duas normas válidas entram em conflito, sendo que uma estatui o direito prima facie, e a outra estabelece a restrição, de modo que o direito definitivo se extrai após a ponderação: para a teoria externa, as normas de direito fundamental não estabelecem comandos definitivos (PEREIRA, 2006, p. 151).

Desse modo, o núcleo essencial dos direitos fundamentais, para a teoria relativa, não pode ser estabelecido de forma meramente estática ou abstrata, mas sim, precisa ser encontrado em cada caso concreto, por intermédio da operação de ponderação, mediante a qual serão determinados os seus limites. 
Aquilo que é essencial depende de condições fáticas e colisões concretas entre direitos e interesses, de modo que o conteúdo essencial de um direito não é sempre o mesmo, podendo variar a cada situação, a depender dos direitos envolvidos em cada caso concreto. Nada mais é do que uma consequência da aplicação da proporcionalidade (SILVA, 2009, p. 196-197).

Conteúdo essencial e proporcionalidade estão intimamente relacionados, pois as restrições que passam no teste da proporcionalidade não podem afetar o conteúdo essencial dos direitos restringidos, o que torna, desse modo, indispensável a operação de ponderação (SILVA, 2009, p. 197).

O sopesamento, ao final, demonstra a primazia de um dos princípios em conflito no caso concreto, sem o aniquilamento do outro, de modo que os princípios, como mandamentos de otimização, pressupõem alguma rigidez do núcleo essencial dos direitos fundamentais. Essa rigidez, contudo, não pode ser completamente estática (CALIL, 2012, p. 85).

Assim, "[...] a teoria externa das restrições, ao admitir o permanente conflito entre princípios, melhor se adapta ao regime jurídico dos direitos fundamentais colocado pela Constituição de 1988" (CALIL, 2012, p. 81), em decorrência até mesmo das múltiplas possibilidades de colisão entre os vários direitos fundamentais consagrados pela Lei Maior.

Ocorre que esse direito fundamental deve ter seu núcleo essencial preservado e este, por sua vez, deverá ser determinado somente no caso concreto, não de maneira abstrata. A partir dessas teorizações, faz-se possível encontrar o seu suporte fático, teoria estudada no tópico a seguir.

\section{O SUPORTE FÁTICO DO DIREITO FUNDAMENTAL DE GREVE}

Apesar de ser um conceito amplamente conhecido pela teoria do direito, a relação do suporte fático com os direitos fundamentais passou a ser estudada no Brasil apenas nos últimos anos. ${ }^{8}$ Referida teoria, po-

8 Por exemplo, em Silva (2009) e Calil (2012). 
rém, pode oferecer uma formulação mais segura para as possibilidades de limitação do direito fundamental de greve.

É um conceito pouco conhecido no direito constitucional brasileiro. É utilizado no direito penal, no conceito de tipo penal, no direito tributário, no sentido da hipótese de incidência e do fato gerador, e no direito privado. No direito constitucional, é aplicável no âmbito dos direitos fundamentais (SILVA, 2009, p. 28).

No sentido dessa teorização, a aplicação dos direitos fundamentais, seja subsunção, sopesamento ou concretização, depende da extensão de seu suporte fático, das exigências de fundamentação concreta, da possibilidade de restrição e da existência de colisões entre direitos fundamentais (SILVA, 2009, p. 68).

O suporte fático abstrato é formado pelos fatos ou atos descritos pela norma, para cuja realização ou ocorrência prevê-se uma consequência jurídica; o suporte fático concreto é a ocorrência no mundo da vida, dos fatos ou atos que a norma jurídica juridicializou. Assim, o suporte fático concreto depende de sua configuração em abstrato (SILVA, 2009, p. 68).

No direito constitucional, o conceito de suporte fático é composto: pelo âmbito de proteção; pela intervenção estatal; e pela fundamentação constitucional que, se não existisse, ensejaria a consequência jurídica do direito fundamental (SILVA, 2009, p. 72-74). Ao abarcar essas dimensões, o suporte fático pode determinar a regra aplicável ao caso concreto.

A consequência jurídica de uma norma ocorre se todas as suas condições forem satisfeitas, situação que permite construir o conceito de suporte fático do direito fundamental, a abarcar a totalidade das condições para que esse direito tenha uma consequência jurídica definitiva (ALEXY, 2008, p. 281-305).

Faz-se necessário incorporar o conceito de intervenção ao suporte fático, pois a abrangência da proteção prima facie depende da extensão dos conceitos de bem protegido e de intervenção. Uma norma só pode restringir um direito fundamental se for constitucional; se não for, pode ser norma interventiva, não restritiva (ALEXY, 2008, p. 305-307). 
Para que a proteção definitiva de um direito fundamental ocorra, o suporte fático tem de ser preenchido, não a cláusula de restrição; se a cláusula de restrição for preenchida e seu suporte fático não, opera-se a restrição. Para tanto, constroem-se duas teorias: a do suporte fático amplo e a do suporte fático restrito (ALEXY, 2008, p. 308), estudadas a seguir.

Caso um direito fundamental seja restringido por uma ação estatal limitativa constitucionalmente fundada, seu âmbito de proteção deve ser demonstrado no caso concreto. Assim, a teoria do suporte fático fornece base segura para uma decisão jurídica sobre direitos fundamentais que os tenha como mandamentos de otimização (CALIL, 2012, p. 75).

Desse modo, no que concerne ao direito fundamental de greve, que não encontra limitações constitucionais expressas, salvo as determináveis por intermédio de lei, a utilização da teoria do suporte fático permite uma aferição possivelmente mais justa das eventuais limitações a esse direito.

\subsection{SUPORTE FÁTICO RESTRITO}

Relacionada às teorias interna dos limites intrínsecos aos direitos fundamentais e do núcleo essencial absoluto, o suporte fático restrito se volta à sua definição abstrata, em relação a todos os seus componentes, dispensando-se, quase que por completo, a operação de sopesamento.

As teorias do suporte fático restrito pregam a falta de garantia a algumas ações, estados ou posições jurídicas que, em abstrato, poderiam subsumir-se ao âmbito de proteção dessas normas e, em geral têm dois aspectos comuns: buscam a essência de um direito ou manifestação humana; e rejeitam a ideia de colisão entre direitos fundamentais (SILVA, 2009, p. 79-92).

Sua principal tarefa é fundamentar aquilo que está incluído ou excluído do âmbito de proteção desses direitos e definir a extensão do conceito de intervenção estatal nesse âmbito. São teorias conservadoras, que impossibilitam a atualização do âmbito de proteção dos direitos fundamentais à realidade cambiante (SILVA, 2009, p. 92-96), 
Isso porque os conceitos de especificidade e tipicidade definem o próprio âmbito da norma, de modo que é difícil saber como se poderia "abrir para o novo". Não bastasse, as defesas do suporte fático restrito geralmente baseiam-se em exemplos estapafúrdios, focados em demonstrar as consequências negativas do suporte fático amplo (SILVA, 2009, p. 96-97).

Trata-se, portanto, de uma teoria cujas bases não são tão sólidas quanto aquelas que têm o sopesamento como elemento essencial, até mesmo no que concerne às exemplificações. Não parece, portanto, suficiente para que se possa definir, com segurança, as possibilidades de limitação ao direito fundamental de greve.

Em decorrência de sua excessiva abstração, a teoria do suporte fático restrito é incompatível com a concretização dos direitos fundamentais na Constituição de 1988, inclusive em razão da considerável quantidade de princípios explícitos em constante colisão, que, por sua vez, não têm restrições intrínsecas (CALIL, 2012, p. 76).

As relações de precedência se tornariam imutáveis. Assim, essa teoria é inaplicável às Constituições, cujas normas não têm hierarquia entre si. A teoria interna se relaciona à teoria do suporte fático restrito, não admitindo conflitos entre normas (CALIL, 2012, p. 80). Trata-se, portanto, de teoria incompatível com os direitos fundamentais da Constituição de 1988.

\subsection{SUPORTE FÁTICO AMPLO}

De modo diferente do suporte fático restrito, a teoria do suporte fático amplo leva em consideração a necessidade da ponderação entre os princípios, especificamente, entre um direito fundamental e sua restrição, de modo que a limitação seja aferida no caso concreto, não em abstrato.

Os juízos sobre direitos fundamentais resultam da operação de sopesamento, que exige uma teoria ampla do suporte fático, que inclua, no âmbito de proteção de cada direito fundamental, tudo aquilo que se volta a protegê-lo, de modo que a definição do âmbito de proteção não basta para definir o suporte fático (ALEXY, 2008, p. 322-323). 
A definição do âmbito de proteção é apenas o primeiro passo, pois a definição das situações abarcadas pelo direito fundamental dependerá do caso concreto, para que seja possível decidir qual o seu âmbito de proteção definitivo. Impõem, assim, uma argumentação voltada a conferir um maior grau de proteção aos direitos fundamentais (SILVA, 2009, p. 109).

Além da ampliação do âmbito de proteção, avulta-se o conceito de intervenção, pois, se a proteção for um direito fundamental a depender da classificação de uma intervenção ou de uma restrição constitucionalmente aceita ou de uma violação inconstitucional, a proteção tende a ser mais efetiva, o que torna mais segura a operação de sopesamento (SILVA, 2009, p. 111-112).

A incorporação das restrições ao suporte fático faz que se necessite aferir sua constitucionalidade no caso concreto. Assim, essas restrições devem ser analisadas sob a técnica da proporcionalidade, pois, ao invés de limites imanentes (abstratos) aos direitos fundamentais, ampliam-se as possibilidades de proteção (prima facie) desses direitos (CALIL, 2012, p. 78).

O conceito de suporte fático amplo é mais adequado à utilização da ponderação para a concretização dos direitos fundamentais na Constituição de 1988, pois considera a existência de conflitos constantes entre os princípios constitucionais (CALIL, 2012, p. 78). Especificamente em relação à greve, necessário aferir eventuais limites legais a esse direito.

\subsection{RESTRIÇÕES AO DIREITO DE GREVE E A LEI 7.783, DE 1989}

A Lei 7.783, do ano de 1989, trata do exercício do direito de greve, estabelecendo, inclusive, limites ao seu exercício, ao regulamentar o parágrafo $1^{\circ}$. do artigo $9^{\circ}$. da Constituição Federal. Referidas limitações são, especialmente, as atividades essenciais e o abuso de direito de greve, conforme definidos pelo diploma. ${ }^{9}$

9 “Art. 9'. Durante a greve, o sindicato ou a comissão de negociação, mediante acordo com a entidade patronal ou diretamente com o empregador, manterá em atividade 
Até porque, juridicamente, a greve é, ao mesmo tempo, um ato complexo e um direito exercido mediante o cumprimento das formalidades legais, que corroboram sua juridicidade, de forma que não se tratam de limites ao exercício do direito fundamental de greve, mas, sim, aos seus condicionamentos (RUPRECHT, 1995, p. 774).

Por exemplo, o artigo $9^{\circ}$. da Lei n. 7.783, de 1989, ao determinar a manutenção de serviços cuja paralisação resulte em prejuízo irreparável ao empregador, amplia a noção de abuso referida pela Constituição, de modo que sua interpretação deve ser restritiva "sob pena de inviabilizar qualquer movimento paredista” (DELGADO, 2009, p. 1.305).

equipes de empregados com o propósito de assegurar os serviços cuja paralisação resultem em prejuízo irreparável, pela deterioração irreversível de bens, máquinas e equipamentos, bem como, a manutenção daqueles essenciais à retomada das atividades da empresa quando da cessação do movimento. Parágrafo único. Não havendo acordo, é assegurado ao empregador, enquanto perdurar a greve, o direito de contratar diretamente os serviços necessários a que se refere este artigo. Art. 10. São considerados serviços ou atividades essenciais: I - tratamento e abastecimento de água; produção e distribuição de energia elétrica, gás e combustíveis; II - assistência médica e hospitalar; III - distribuição e comercialização de medicamentos e alimentos; IV - funerários; V - transporte coletivo; VI - captação e tratamento de esgoto e lixo; VII - telecomunicações; VIII - guarda, uso e controle de substâncias radioativas, equipamentos e materiais nucleares; IX - processamento de dados ligados a serviços essenciais; X - controle de tráfego aéreo; XI compensação bancária. Art. 11. Nos serviços ou atividades essenciais, os sindicatos, os empregadores e os trabalhadores ficam obrigados, de comum acordo, a garantir, durante a greve, a prestação dos serviços indispensáveis ao atendimento das necessidades inadiáveis da comunidade. Parágrafo único. São necessidades inadiáveis da comunidade aquelas que, não atendidas, coloquem em perigo iminente a sobrevivência, a saúde ou a segurança da população. Art. 12. No caso de inobservância do disposto no artigo anterior, o Poder Público assegurará a prestação dos serviços indispensáveis. Art. 13. Na greve, em serviços ou atividades essenciais, ficam as entidades sindicais ou os trabalhadores, conforme o caso, obrigados a comunicar a decisão aos empregadores e aos usuários com antecedência mínima de 72 (setenta e duas) horas da paralisação. Art. 14. Constitui abuso do direito de greve a inobservância das normas contidas na presente Lei, bem como, a manutenção da paralisação após a celebração de acordo, convenção ou decisão da Justiça do Trabalho. Parágrafo único. Na vigência de acordo, convenção ou sentença normativa não constitui abuso do exercício do direito de greve a paralisação que: I - tenha por objetivo exigir o cumprimento de cláusula ou condição; II - seja motivada pela superveniência de fatos novo ou acontecimento imprevisto que modifique substancialmente a relação de trabalho" (BRASIL, 1989, n.s.p.). 
Os requisitos formais que devem ser observados para validar o movimento grevista não se chocam com a Constituição, voltando-se apenas a "civilizar o exercício desse direito" (DELGADO, 2009, p. 1.306). Nesse sentido é que se faz necessário aplicar, a esse direito, a teoria externa dos limites, relativa do núcleo essencial e a do suporte fático relativo.

O exercício do direito de greve, v.g. por todos os trabalhadores da saúde, não poderia ser admitido, sob pena de se arriscar a sobrevivência da população. Dessa situação de colisão entre direitos fundamentais resulta a necessidade de se ponderarem interesses e direitos (SARMENTO, 2000, p. 154).

Até mesmo porque, em não se havendo o processo de ponderação, o conflito entre esses direitos teria de ser resolvido por meio de uma hierarquização arbitrária entre eles, eliminando-se os direitos que o intérprete, sob mera discricionariedade, resultante de sua mera opinião, considerasse menos importantes (SARMENTO, 2000, p. 154).

Isso posto, caso o direito fundamental de greve venha a colidir com outro direito fundamental ou princípio constitucional, faz-se necessário proceder à operação de sopesamento, na medida em que a Lei 7.783 é protocolar, nada mais fazendo do que estabelecer formalidades para o seu regular exercício.

\section{A PONDERAÇÃo E O DIREITO DE GREVE NA JURISPRUDÊNCIA}

A jurisprudência do Tribunal Superior do Trabalho, bem como, a jurisprudência do Supremo Tribunal Federal, estabelecem a necessidade de ponderação entre o direito fundamental de greve e outros princípios constitucionais, de modo a que se possa estabelecer, assim, a legitimidade dessas limitações.

Inicialmente, o Tribunal Superior do Trabalho entendeu, em dissídio coletivo, pela necessidade de um juízo de ponderação entre o direito de greve e a "realidade socioeconômica pela qual passa o país", tendo 
afirmado, apesar disso, que é necessário o pagamento dos dias de paralisação, preservando, assim, o núcleo essencial do referido direito. ${ }^{10}$

Nesse sentido, o Supremo Tribunal Federal decidiu, em uma greve, pela necessidade de ponderação entre o direito de livre manifestação e o direito de propriedade, a liberdade de ir e vir e de trabalhar, mantendo, porém, o núcleo essencial do direito de greve, restringindo, porém, a paralização forçada de empregados que não queiram aderir ao movimento. ${ }^{11}$

10 "RECURSO ORDINÁRIO. DISSÍDIO COLETIVO DE GREVE E DE NATUREZA ECONÔMICA. SOCIEDADE DE ECONOMIA MISTA. SITUAÇÃO ECONÔMICA DEFICITÁRIA. PROJEÇÃO DO ÍNDICE DE REAJUSTE SALARIAL NAS DEMAIS CLÁUSULAS DE NATUREZA ECONÔMICA. JUÍZO DE PONDERAÇÃO. A jurisprudência desta Seção Especializada é pacífica no entendimento de que determinadas cláusulas econômicas preexistentes devem ser reajustadas com o mesmo índice fixado para o reajuste salarial. Não obstante, devem-se levar em conta alguns aspectos no caso concreto, como a situação econômica precária da Empresa, a exemplo de tantas outras da Administração Indireta; a preservação dos postos de trabalho em detrimento de maiores vantagens pecuniárias para o período; a razoabilidade do pleito e a mudança de paradigma, aqui revelada no julgamento do acenado Processo n. ${ }^{\circ}$ TST-RO - 296-96.2015.5.10.0000, como elemento ponderador capaz de equacionar os anseios da categoria profissional à realidade socioeconômica por que passa o País. Recurso Ordinário provido. GREVE. COMPENSAÇÃO DOS DIAS PARADOS. MORA SALARIAL. DESCUMPRIMENTO DE ACORDO COLETIVO DE TRABALHO. É devido o pagamento dos salários relativos aos dias de paralisação da greve, quando deflagrada em razão de mora salarial e/ ou descumprimento de instrumento coletivo de trabalho, como no caso. Recurso Ordinário não provido. CONDENAÇÃO AO PAGAMENTO DOS SALÁRIOS E DEMAIS PARCELAS EM ATRASO. APLICAÇÃO DE MULTA POR DESCUMPRIMENTO DA DECISÃO. PEDIDO CALCADO NA EXCLUSÃO DA MULTA. Conquanto relacionada aos motivos da greve, a determinação de pagamento dos salários atrasados, assim como de outras parcelas decorrentes de lei ou de instrumento coletivo, é própria dos dissídios individuais [...]" (BRASIL, 2017, n.p.).

11 " [...] 3. Evidente que estamos diante de dois direitos constitucionalmente garantidos: o direito de livre manifestação, disposto no art. $5^{\circ}$., XVI da CF, e o direito de propriedade, liberdade de ir e vir e de trabalho, igualmente presentes no mesmo art. $5^{\circ}$. da $\mathrm{CF}$, havendo de se buscar um equilíbrio que não afaste nenhum deles. 4 . $\mathrm{O}$ deferimento do pleito autoral não tem como consequência a negação ou o afastamento do direito fundamental de realização de greves, pois, a toda evidência, lhe é permitido o exercício deste direito e a convocação de todos os pertencentes à categoria, mas o exercício desse direito há de se fazer de forma a não impedir a liberdade daqueles que não concordarem com a postura do sindicado apelado, sob pena de se converter a convocação à greve em autêntico abuso de direito [...]" (BRASIL, 2018, n.p.). 
Nota-se, assim, que o direito fundamental de greve não tem restrições em abstrato, sendo que as suas limitações deverão ser aferidas no caso concreto, por intermédio da operação de sopesamento. Em assim sendo, pode-se depreender que a sua estrutura normativa se adapta à teoria externa dos limites aos direitos fundamentais, à teoria relativa do núcleo essencial, bem como, ao suporte fático amplo.

\section{CONSIDERAÇões FINAIS}

O direito de greve, desde as suas origens, liga-se aos movimentos coletivos de trabalhadores, bem como, mostra tentativas de sua restrição, por diversos fatores. Mesmo no período prévio à Revolução Francesa, quando não se cogitavam direitos trabalhistas, já era possível identificar movimentos classistas.

Os movimentos paredistas ocorridos no final do Século XIX e início do Século XX foram indispensáveis para o surgimento desse ramo do direito. No Brasil, a primeira regulamentação surgiu ainda no final do Século XIX, adiantando-se em relação a outras nações.

Os vários movimentos grevistas ocorridos no período demonstraram a necessidade de regulamentação desse direito que ocorreu de maneira efetiva em algumas das Constituições anteriores, porém, de maneira intermitente. Somente em 1988 é que se transformou em um direito amplamente reconhecido.

Reconhece-se, nesse sentido, a relação direta entre o direito de greve e os regimes democráticos. Ocorre que a greve e o direito de greve não se confundem, pois o primeiro é a materialização do segundo. Aquele é previsto pelo artigo $9^{\circ}$., da Constituição Federal de 1988, cujo caput determina aos trabalhadores a decisão acerca de seu exercício.

Trata-se, nesse sentido, de uma norma de eficácia plena. O $\S 1^{\circ}$. do dispositivo, porém, determina a regulamentação infraconstitucional dos serviços e atividades essenciais e das necessidades inadiáveis da comunidade. Apesar de ser possível afirmar que se trata de uma norma de eficácia limitada é, sim, uma norma restritiva, carente de regulamentação. 
Quanto aos servidores públicos, o artigo 37, VII, demanda regulamentação infraconstitucional, por intermédio de lei específica, demonstrando-se que se trata de norma constitucional de eficácia limitada, da maneira como foi reconhecido pelo Supremo Tribunal Federal.

O direito de greve consta do Capítulo II ("Dos Direitos Sociais") do Título II ("Dos Direitos e Garantias Individuais") da Constituição, de forma que, topologicamente, é um direito fundamental. Trata-se de uma norma principiológica, submetendo-se, portanto, à ponderação por ocasião de eventual conflito com outro princípio.

As diferenças existentes entre princípios e regras é, inicialmente, estrutural, em decorrência do fato de que aqueles têm estrutura semântica mais ampla e abstrata do que estas. Além disso, os conflitos entre regras se resolvem por meio da lógica do tudo-ou-nada e, entre os princípios, mediante a ponderação.

A ponderação ocorre por meio da operação de sopesamento, que se volta a determinar a norma aplicável ao caso concreto. Essa operação, todavia, não elimina completamente a incidência do princípio derrotado, de maneira que se faz necessário preservar seu conteúdo essencial, que é explicado mediante duas teorias diferentes.

A primeira, relacionada à teoria interna dos limites aos direitos fundamentais, que determina que a Constituição estabelece limites prévios aos direitos fundamentais, em abstrato, ignorando a necessidade de ponderação entre princípios. Ocorre que, em relação ao direito de greve, por não haver limites constitucionais expressos, o sopesamento é necessário.

Nesse sentido, a teoria externa dos limites aos direitos fundamentais, vinculada à teoria do núcleo essencial relativo, que demanda a ponderação entre os princípios conflitantes, é a mais adequada ao tratamento do direito de greve. Essa teorização relaciona-se, também, à teoria do núcleo essencial dos direitos fundamentais, que comporta as teorias relativa e absoluta.

A teoria relativa, ao contrário da teoria absoluta, determina que o suporte fático não pode ser estabelecido de forma abstrata, necessitando, para tanto, encontrar-se, caso a caso, sua norma de incidência, seu 
núcleo essencial e seu suporte fático, fazendo que a operação de ponderação seja determinada.

O direito fundamental de greve, portanto, pode ser limitado, contudo, apenas no caso concreto. A Lei 7.783, do ano de 1989, que trata do exercício do direito de greve, estabelece limites ao seu exercício, ao regulamentar o $\S 1^{\circ}$. do artigo $9^{\circ}$. da Constituição Federal, especialmente no que se relaciona às atividades essenciais e ao abuso de direito de greve.

Referido diploma, todavia, não trata de limites ao exercício do direito fundamental de greve, mas, sim, aos seus condicionamentos, voltados ao seu exercício civilizado, de modo que é necessário proceder-se à operação de sopesamento. Trata-se de entendimento corroborado pela jurisprudência do Tribunal Superior do Trabalho e do Supremo Tribunal Federal.

\section{REFERÊNCIAS}

ALEXY, Robert. Teoria dos direitos fundamentais. São Paulo: Malheiros, 2008.

BRASIL. Tribunal Superior do Trabalho. ARR 1001741320165010031. Relatora: Ministra Maria de Assis Calsing. Publicação: 5 maio 2017. Disponível em: www.tst.jus.br. Acesso em: 16 nov. 2018.

BRASIL. Supremo Tribunal Federal. Mandado de Injunção 712-PA, Relator: Ministro Eros Grau. Publicação: 31 out. 2008. Disponível em: www.stf.jus.br. Acesso em: 16 nov. 2018.

BRASIL. Supremo Tribunal Federal. RE: 601828-RJ. Relator: Ministro Alexandre de Moraes. 2 mar. 2018. Disponível em: www.stf.jus.br. Acesso em: 16 nov. 2018.

CALIL, Mário Lúcio Garcez. A teoria do suporte fático aplicada ao regime jurídico dos direitos fundamentais da Constituição da República de 1988. Em Tempo, v. 11, p. 70-87, dez. 2012.

. OLIVEIRA, Rafael Sérgio Lima de. Hermenêutica do princípio republicano: o caminho para a compreensão da fazenda pública. Universitária: 
revista do curso de mestrado em direito. Araçatuba, v. 8, n. 1, p. 74-105, jan./ jul. 2008.

DELGADO, Mauricio Godinho. Curso de direito do trabalho, 8. ed. São Paulo: LTr, 2009.

DIMOULIS, Dimitri; MARTINS, Leonardo. Teoria geral dos direitos fundamentais. São Paulo: RT, 2008.

DWORKIN, Ronald. Levando os direitos a sério. São Paulo: Martins Fontes, 2007.

MELLO, Maildes Alves de. A greve no direito positivo brasileiro. Porto Alegre: Síntese, 1980.

NASCIMENTO, Amauri Mascaro. Compêndio de direito sindical, 2. ed. São Paulo: LTr, 1989.

PEREIRA, Jane Reis Gonçalves. Interpretação constitucional e direitos fundamentais. Rio de Janeiro: Renovar, 2006.

RUPRECHT, Alfredo J. Relações coletivas de trabalho. Trad.: Edilson Alkmin Cunha. São Paulo: LTr, 1995.

SARMENTO, Daniel. A ponderação de interesses na Constituição Federal. Rio de Janeiro: Lumen Juris, 2000.

SCHOLLER, Heinrich. O princípio da proporcionalidade no direito constitucional e administrativo da Alemanha. Interesse Público, v. 1, n. 2, p. 93-107, abr./jul. 1999.

SILVA, José Afonso da. Aplicabilidade das normas constitucionais, 6. ed. São Paulo: Malheiros, 2003.

SILVA, Virgílio Afonso da. Direitos fundamentais: conteúdo essencial, restrições e eficácia. São Paulo: Malheiros, 2009.

SÜSSEKIND, Arnaldo. Direitos sociais na constituinte. Rio de Janeiro: Editora Jurídica Freitas Barros, 1986. 


\section{Sobre os autores}

\section{Debora Markman}

Graduada em Direito pela Universidade Presbiteriana Mackenzie. Especialista em Direito do Trabalho, Direito Previdenciário e Direito Constitucional pela Faculdade Dom Alberto. Mestranda pela Universidade Metodista de Piracicaba - UNIMEP.

E-mail: deboramark@icloud.com

\section{Mário Lúcio Garcez Calil}

Pós-doutorado pela Fundação de Ensino Euripedes Soares de Rocha (Marília-SP). Doutor em Direito pela Faculdade de Direito de Bauru (CEUB-ITE). Professor Ajunto IV da Universidade Estadual do Mato Grosso do Sul - Unidade Universitária de Paranaíba.

E-mail: mario.cali1@yahoo.com.br

Submetido em: 11-12-2018

Aceito em: 17-12-2018 